\title{
NUCLEAR POWER CAN BE THE ANSWER
}

\author{
R. G. BOOTHROYD \\ Chartered Engineer, Queensland, Australia.
}

\begin{abstract}
This paper reviews the development of fast molten salt nuclear reactors (MSRs) to close the nuclear fuel cycle by processing future and existing nuclear waste so that it can be returned safely to the environment. It follows two earlier papers outlining the overall use of a range of MSR types and an outline of future proposed marketing of a universal modular thermal MSR design for general purposes. It is suggested that the future MSR industry will probably evolve into three major competitive global corporations. The first one, serving the Far East, seems likely to become entirely MSR based, whereas the other two serving Europe/Western Russia and the Americas may use the alternative lead-cooled fast reactor for waste disposal, which is the closest competitor to the MSR system. Although construction of full-scale fast (MSR) reactors for closing the fuel cycle may not eventuate until some years into the future, it is concluded that this need not delay the introduction of the general purpose thermal MSR reactor envisaged earlier. This new nuclear technology is considered essential to maintain base-load electricity in a world where agricultural needs are expected to take precedence over space requirements for wind and solar farms. Using Thorium, in addition to Uranium, nuclear fuel is sufficient for the next 1000 years. Thus this energy resource can be considered pseudo-sustainable and give us the time to restore our world to a state of balance and true sustainability. Attention is also drawn to the present dangers of continuing to increase the storage of nuclear waste and the refurbishing of old-design nuclear plant, which are already 40 years old.
\end{abstract}

Keywords: GIF, molten salt nuclear power, nuclear safety and licencing

\section{INTRODUCTION}

Reputedly [1] it was Edward Teller, one of the pioneers of our nuclear age, who 'saddled the power reactor industry with the almost impossibly expensive requirement of perfect safety' [1, p. 2]. It was reasonable enough for nuclear engineers of that time to find such a specification completely unrealistic. This was the pioneering age of the American PWR and the British Magnox gas cooled reactors. It is a credit to our good engineering at that time that nuclear mishaps were so few although there were many other subsequent anxious moments [2]. In fairness to the nuclear industry, the gross disasters of Chernobyl and Fukushima can be attributed largely to human greed taking precedence over human safety. This is an industry where cutting costs for higher apparent economic efficiency has to be evaluated very critically in the interests of public safety.

Apart from confirming the need for a revamped and modernised nuclear power industry, this paper is concerned specifically with the techniques needed to treat all nuclear waste to a form which is as harmless as possible.

To a large extent the neglect to continue the original molten salt reactor research carried out at Oak Ridge, Tennessee will go down in history as one the most costly management mistakes of all time. Nevertheless the reasons for this are understandable [3]. It was a case of trying to achieve too much with an inadequate budget.

The title of this paper is a deliberately contradictory rephrasing of the title of Dr Helen Caldicott's excellent and well-reasoned, yet very critical, book [2]. Both Teller and Caldicott were right. Nuclear power has to be perfectly safe. Although Caldicott examined and was critical of Generation IV nuclear reactors, she made no mention of the molten salt 
reactor, which was one of the six new reactor types considered in 2002 for Generation IV development. These are:

1. Liquid Sodium Fast Reactor (SFR)

2. Helium Cooled Fast Reactor (HeFR)

3. Liquid Lead Fast Reactor (LFR)

4. Supercritical Water Fast Reactor (SCFR)

5. Molten Salt Fast Reactor (FSMSR)

6. Very High Temperature Thermal Reactor (VHTR)

The first five of these are fast neutron spectrum reactors and any one of them could be considered for burning up the long-lived actinides to allow nuclear waste to be disposed of safely. It is reasonable to presume that reactor (5), the FSMSR, would be the safest but it is questionable if it would also be the least expensive. The nearest safe and competitive system is the LFR considered later in section (8.6).

Naturally it is reasonable to claim that nothing can ever be perfect in our world. Yet there are many examples in modern technology where near perfection has already been achieved. At least the following examples from the transport industries may encourage us to advance towards safe nuclear reactor technology that the present author claims to be a vital necessity in tomorrow's world.

\section{SOME RECENT EXAMPLES OF NEAR PERFECT TECHNOLOGY}

In the last 20 years or so the transport industries have experienced striking developments in improved public safety. Common examples are huge reliable slow-speed diesel engines for large ships; wide-bodied airliners, which are safe with only two engines; and, perhaps most conspicuous of all, private motor cars designed for exceptional safety with prohibitively expensive maintenance costs compelling owners to send the vehicle to the scrap-yard when this is desirable.

\section{DEVELOPING A FAST NEUTRON SPECTRUM MOLTEN SALT REACTOR (FSMSR)}

Whereas the research at Oak Ridge gave sufficient data and experience for designing a thermal MSR [4, 5], the design of a fast neutron spectrum FSMSR, without similar previous practical experience, is a much more daunting task. Yet fundamentally the fast reactor is a much more simple device. The reactor core is nothing more than an empty tank with numerous pipe connections. The mathematical techniques for fast reactor design are just as reliable and well-established as for thermal neutrons. The uncertain design factors lie mainly in corrosion and fast neutron damage to present-day construction materials. Longevity and reliability is a necessary feature for an FSMSR. These qualities are needed to breed more fuel or burn up nuclear waste while working steadily, and trouble free, to supply base-load electricity from these activities.

\subsection{Suggested management plan for developing an FSMSR}

A finalised FSMSR design needs to be configurable to a variety of uses. This is easy enough to achieve and may include:

a. Breeding more fuel, which must be removed continuously from the reactor to maintain the low range of criticality desired in MSRs. 
b. Burning up nuclear waste. This waste is merely used as new fuel. In a base-load facility waste may be injected in solid form. Alternatively the waste may be injected in liquid halide (fluoride or chloride) form as recommended for the thermal reactor [4].

c. Acting as a fuel converter the reactor breeds only part of the fuel it needs. The extra fuel may come from fissile or fertile waste or another source of fuel such as unwanted Plutonium.

d. Often it may carry out all the above tasks concurrently, or alternately, while delivering steady power to the Grid.

\subsubsection{Core designs}

Reactor core designs are of two main types described in the following sub-sections:

\subsubsection{Integral designs}

In these reactors, the primary heat exchangers (PHE in Figure 1) surround the core and give considerable protection to the reactor container from damage by fast neutrons. Redundancy is designed into such a system by using surplus primary heat exchangers. If one goes wrong, it can be isolated. This is essential because integrally-located primary heat exchangers cannot be replaced except by shutting down the reactor for a major overhaul. By contrast a defective pump is easier to replace as they are more easily accessed from the top of the reactor without shutting down the plant. Pump impellers are at the bottom end of a long vertical bearing-supported shaft.

It is expected that all finalised FSMSR designs will be integral ones [6].

\subsubsection{Loop designs}

In this design the primary heat exchangers are external to the core exactly as depicted in the schematic Figure 1.The core vessel will need protection from fast neutrons and alternatively this can also be provided by a breeder blanket of fertile material such as Thorium or depleted Uranium, or even a neutron reflector. Because the core pressure is close to atmospheric pressure it is of thin-walled construction. The inside surface can be of nickel-based alloy that resists corrosion but this material is prone to embrittlement by fast neutrons. The outside of the core could be of martensitic-ferritic steel, which stands up better to fast neutron damage [7].

It is suggested that the first FSMSR prototype should be a single unit developed from a loop design. This loop design gives greater flexibility in adapting the prototype reactor to

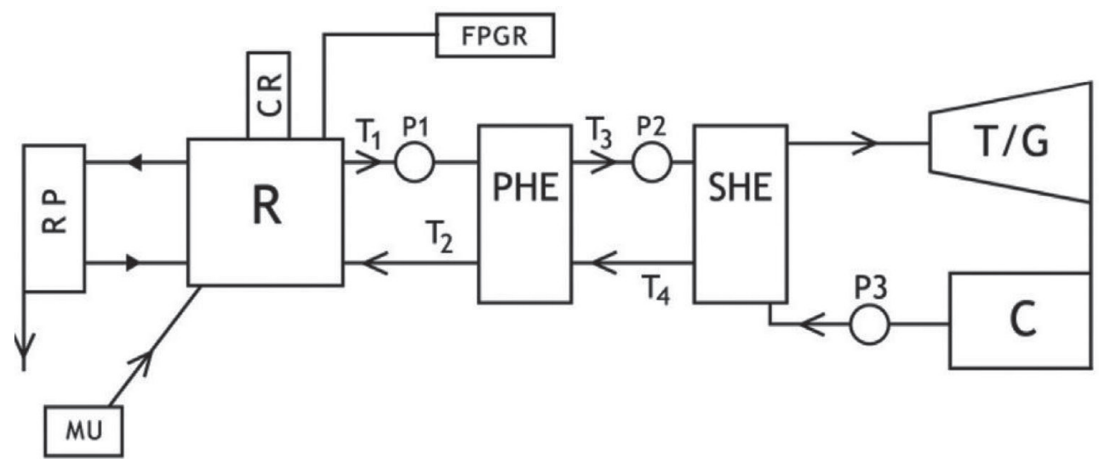

Figure 1: schematic layout of molten salt reactors (see Appendix I for symbol list). 
alternative design concepts for testing even though the finalised design will inevitably be intended to be the integral design described in section 3.1.1.1.

\section{REVIEW OF PRESENT-DAY RESEARCH: THE PROBLEM OF MANY CHOICES}

As a general conclusion it seems that the optimisation of the final design for an FSMSR for burning up nuclear waste is still many years away in the future. A review of the latest reports [8-15] indicates this. The main cause is much the same as the one that caused the cancellation of the original project at Oak ridge. Too many tasks are being attempted at once by too many organisations with insufficient financial backing. China has allocated $\$ 350$ million to start its work but this has to be shared around many tasks. One of these is to use molten salt coolant for encapsulated fuel.

No FSMSR has ever been built but desktop studies have shown beyond any doubt that this technology is well within our grasp. The European EVOL reactor $[6,8]$ is one such example as is the Russian MOSART study [12] designed specifically to burn up LWR/unwanted Plutonium waste as well as producing valuable materials by nuclear transmutation.

The planned research by China can be expected to leapfrog these earlier designs. China is reported to have ambitions to secure world-wide intellectual property rights from its work. In passing it seems appropriate to point out that the final design of FSMSR will result from work from many nations. Perhaps we should seek a prior international agreement that property rights should be distributed according to the investment made after adjusting for inflation?

These problems from continued technological improvement (which can be expected to delay design decisions) can be illustrated by the latent potential of an earlier study [7] now covered in the following section.

\section{SHOULD WE USE CHLORIDE-BASED SALTS INSTEAD OF FLUORIDE SALTS?}

The EVOL design $[6,8]$ uses much very expensive lithium 7 fluoride at $99.995 \%$ purity. This must be separated from its other natural isotope lithium 6 that would break down to dangerous contaminant Tritium in the reactor. Ignatiev, in his latest report [10], also draws attention to the solubility of actinide trifluorides being very close to their maximum possible solubility. He also draws attention to the problems caused by treating a range of actinides. It is possible to avoid these problems by raising the temperature in the reactor but this reduces the longevity of reactor materials from corrosion. Burning up waste takes a long time so we need a reactor which will work for a long time without major maintenance.

Using lithium fluoride is attractive for designers because we have more experience with this salt than any other. However the solubility of actinide chlorides is reported to be higher in cheaper sodium or potassium chloride salt, although the corrosion chemistry of these salts is one which is more complicated and a subject in which we have much less experience. Note that this corrosion has no relationship with common water-enhanced corrosion with which we are more familiar.

There are other attractions in using chloride ions. One of these is that it is attractive to use molten chloride technology in pyroprocessing (see section 8.3-8.3.1) and it is desirable to have similar reactants in fission product/actinide partitioning and in the reactor itself.

Figure 2 compares the calculated neutron spectra in different salt mixtures. The red spectrum, which is the top mix in the inserted table in Figure 2, uses a traditional beryllium/ lithium mix and it has the disadvantage of a soft (more thermal) neutron spectrum shown well to the left of the other five spectra. The second mix is a sodium/zirconium/ lead mix (shown in yellow). The green spectrum shows a distinctly harder fast spectrum. The best is the last 


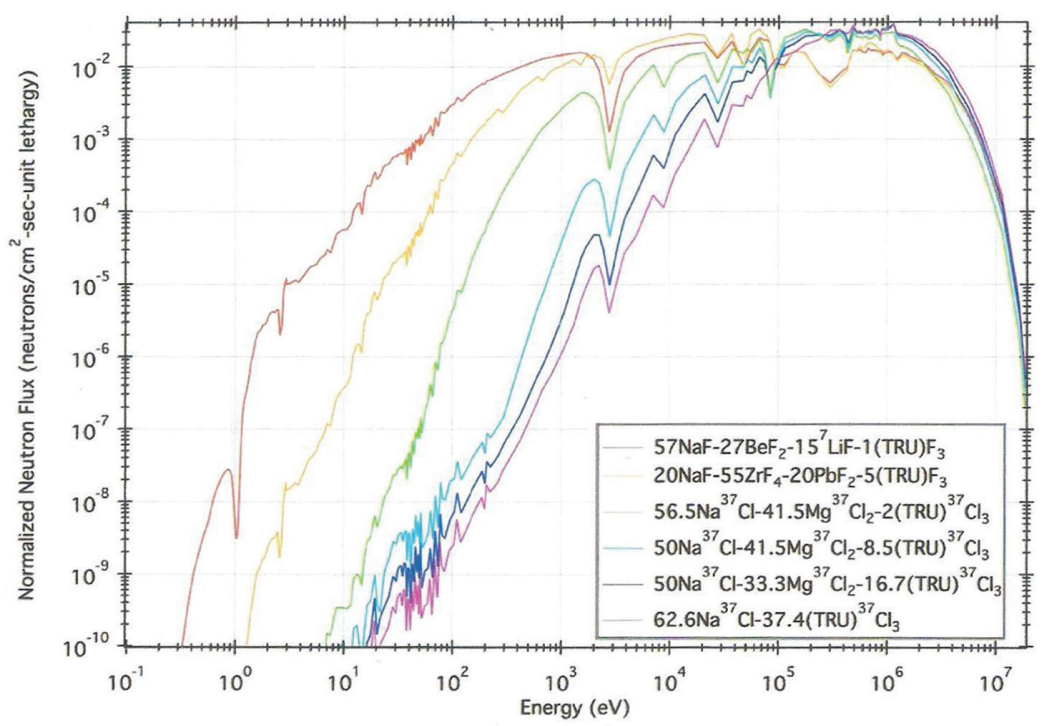

Figure 2: Calculated neutron spectra for different molten salts (source from Ref [7]). The numbers, which precede the salts, are the molar \% in the mixture; TRU (trans uranium elements) is another term for the actinide salt content

spectrum shown in purple but it only has actinides and pure sodium chloride. The $5^{\text {th }}$ and $6^{\text {th }}$ spectra containing magnesium-37 improve the corrosion chemistry yet still preserve a true fast neutron spectrum. Fast neutrons have much lower absorption cross sections with nuclei. There is an advantage, therefore, in inserting Thorium into the reactor in the later stages of actinide destruction. This fertile Thorium breeds Uranium-233 fuel after decaying from intermediate product ${ }^{233} \mathrm{~Pa}$. By keeping a faster neutron spectrum, absorption losses of protactinium (Pa) by thermal neutrons are minimised. It is the late ${ }^{233} \mathrm{U}$ injection which is particularly useful in destroying long-lived actinides. This is because ${ }^{233} \mathrm{U}$ produces few actinides itself. In order to produce actinides ${ }^{233} \mathrm{U}$ would need to absorb consecutive neutrons itself for this to be possible and this has a low probability (also see Appendix III, describing subcritical reactors).

There is another complication with chloride salts in that it is necessary to separate isotope ${ }^{37} \mathrm{Cl}$ from its other natural isotope ${ }^{35} \mathrm{Cl}$. Although this can be done, the economics of the process have not yet been fully investigated [7]. ${ }^{35} \mathrm{Cl}$ changes in the reactor to ${ }^{36} \mathrm{Cl}$ which is a long-lived beta-particle emitter. To generate ${ }^{36} \mathrm{Cl}$ would defeat the object of burning up dangerous long-lived radioactive materials, which is to render the waste harmless.

\section{PROTECTING MSRs FROM ACTS OF TERRORISM}

The mass-produced thermal reactor described in detail in Ref [4] is very different from the much larger 'nuclear town' complex described in the present paper. For terrorists the former is a 'hard' target, whereas the nuclear complex is a 'soft' and attractive target.

All the working parts of the thermal reactor [4] are heavily shielded and underground beneath thick reinforced concrete. Little comment was made in the original paper [4] regarding the lifting gear required for servicing this reactor. Nevertheless external road-level lifting 
gear will be needed to lift casked radioactive materials on to heavy trucks for transport to the nuclear complex. This heavy steel lifting structure can also serve to protect the underground reactor from a large hijacked aircraft such as an Airbus A380. The large channel stanchions would sacrificially tear the wings and 4 engines off the crashing aircraft decreasing the momentum of heavy components. The enormous resulting fireball would have no effect on the underground reactor which would be expected to continue functioning normally.

For the nuclear complex (described in the present paper and outlined in the earlier ones $[4,5]$ ) it is suggested that the whole complex be declared a registered 'no fly zone'. Anti-aircraft missiles could be programmed to destroy any airborne intruder automatically. This action would be preceded by radio warnings and radar-directed light beams to warn accidental intruders.

It follows that the nuclear complex can only be accessed by road or rail. This is considered essential. There may be as many as 10,000 well-paid workers in such a large nuclear town complex. Most of them would reside there during the working week. Also most of them would work above ground. As well-paid staff, many would probably transfer to their holiday homes outside the complex for recreation or at week-ends. The high-level security system needed is a much updated version of systems used many years ago for UK government research establishments.

\section{ULTIMATE DISPOSAL OF WASTE}

After approximately 300 years, in principle, it will be possible to release fast reactor treated waste as an ash which is no more dangerous than uranium ore when it is first mined. Almost inevitably there will be arguments between our financial advisers and public safety engineers as to the final acceptable quality of disposable nuclear waste (see Appendix III). In any event we need to keep an open mind with regard to possible future developments in nuclear technology. For example, perhaps we should remind ourselves that nuclear reaction cross sections are only a mathematical device, which allows us to use mathematical equations of convenience in reactor design. Every nuclear reaction is in reality a quantum event. It is not a simple matter of a minute nuclear missile such as a neutron hitting an atomic nucleus, which looks like the board we use for playing a game of darts. Interacting particles can form a compound nucleus and this complicated event is easier when conditions suitable for a resonance exist. The effects of these resonances can be seen at specific energies as shown in the spectra in Figure 2. Perhaps we may be able eventually to exploit quantum phenomena in further reducing long-lived actinides in nuclear waste?

A well-established method of enhancing the quality of nuclear waste is to use a subcritical assembly. This is described in Appendix III.

Disposing of harmless nuclear waste will be a new experience for us all. It will probably proceed as follows in the nuclear complex towns proposed.

When treatment in the FSMSR is complete and a major service and shutdown is due, the molten salt will be poisoned with a strong thermal neutron absorber to prevent criticality accidents. The molten salt will then be pumped into smaller containers in a heavily shielded production line. The containers are likely to be of stainless steel. These are then enclosed individually in a heavy steel cask to shield operators from the intense gamma radiation and transported to a nearby underground repository for 300 years using remote handling machinery. Newly filled containers will need forced air cooling initially but the salt will soon solidify and radiation declines quickly at first, eventually allowing cooling equipment to be removed when natural convection of residual heat is enough. Remote handling would be used throughout this stage. 
After 300 years the containers can be handled like anything else and they are then taken to another production line for the extraction of valuable elements. Presumably in 300 years we will have worked out the complicated chemical methods, which are necessary in this very involved refinery process. This production line would be fully enclosed to prevent loss of contaminating dust but heavy radiation shielding is not needed. Operators would use remote handling techniques for carrying out tasks within the enclosed production line. The final waste is then subjected to a vitrification process and installed in stainless steel drums for final disposal in a waste repository. This may be in a distant but suitable location such as an abandoned salt mine in a geologically stable area.

Many of the valuable materials extracted from the waste will be the so called 'noble' metals. One example is rhodium, which is extremely useful in chemical catalysis. Rhodium hardly exists at all in any known natural ore. Today Rhodium is extracted as a contaminant of other noble metals such as Platinum The world price of Rhodium peaked at US\$350,000/kg in 2008. Nuclear transmutation can probably stabilise the price closer to US\$25,000/kg.

\section{A SUMMARY OF IMPORTANT TASKS AHEAD OF US}

\subsection{Adequacy of important construction materials for MSRs}

Because MSRs are inherently high temperature devices (see Figure 1 in Ref. [4]) they are fundamentally very efficient in the thermodynamic sense. Yet reactors must be designed to function reliably for long periods. Inevitably our early MSR designs must be less efficient than we would like because we have not yet developed better materials to withstand high temperatures in a high and fast neutron flux.

Figure 3 shows just one of many anticipated different forms of industrial plant, which will need hydrogen generated from high temperature MSRs. Some of these industries will be inside the nuclear town and others will be outside. The nuclear industry has a record of heavy expenditure on materials science in the past and inevitably this will happen again in the future.

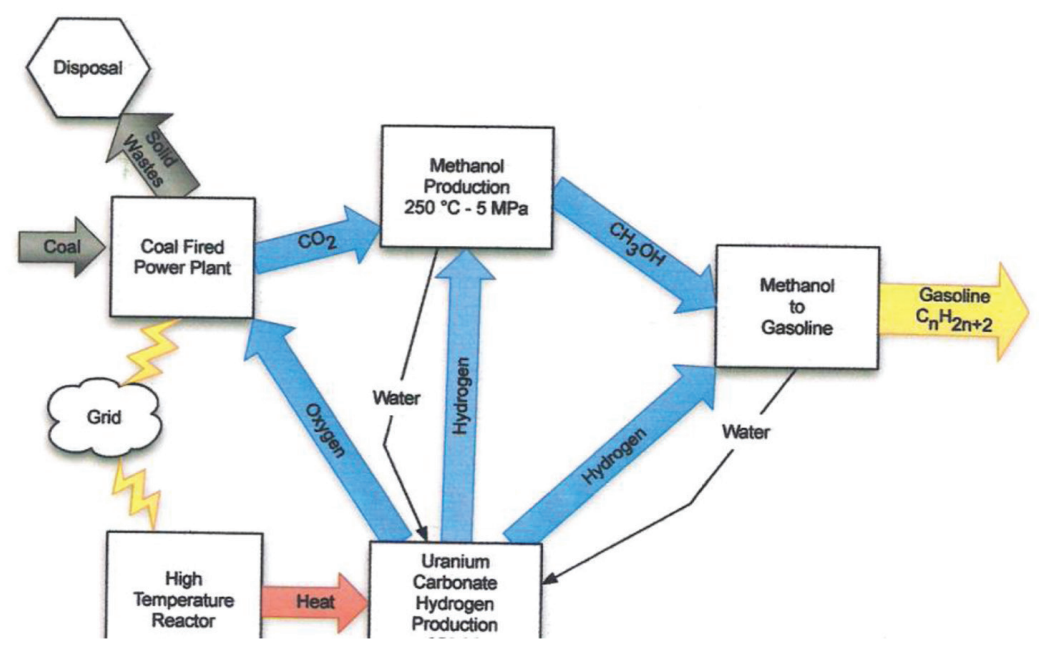

Figure 3: Example of use of a future high temperature MSR (source Ref. [7]). 


\subsection{Introduction of the co-generation Brayton cycle in electrical power generators}

For the reasons given in section 8.1, MSR electrical power generators cannot yet achieve thermodynamic efficiencies approaching $60 \%$ until we have better materials at our disposal. The co-generation Brayton gas turbine cycle [15] is ideally suited to MSR technology. One important reason is that the water-based steam cycle deriving from heat from the gas turbine exhaust is isolated completely from the nuclear reactor system. Almost all of our earlier nuclear reactors have used water, or heavy water. Yet nuclear reactors and water are fundamentally incompatible with each other. We learnt this lesson the hard way at Fukushima.

\subsection{On-line fission product removal}

This complicated technology is still in a development stage, although fundamentals are well advanced and eventual success in this technology is assured. Fast reactors are much more tolerant of fission product build up than thermal reactors. Yet both systems would benefit from improved methods in this area. It seems likely that batch methods of fission product removal will be used rather than the more idealised continuous method because batch treatment simplifies design.

Europe's Evol reactor design [6] specifies a daily removal of between 10 and 40 litres of coolant/fuel from the reactor core. This quantity would be subjected to the process of separating fission products and remaining fissile/fertile elements. The former would be directed to a waste container specified in section 7, whereas the latter would go to another container awaiting reinjection into the reactor, with other waste awaiting burn-up treatment. FSMSRs are like all MSRs and require the nuclear reactants in the core to be kept within close limits as determined from measuring the reactor coolant/fuel temperatures and the flow rate of coolant/fuel through the reactor. Accumulation of reinjectables would occur when fertile material such as thorium is added to the reactor. Although computers would keep logged records of these quantities, essentially these actions would be under constant human supervision in addition to natural reactor controls.

\subsubsection{Adaptation of existing technology}

At most only about $5 \%$ of available fuel is usable in encapsulated fuel elements before the fuel needs to be reprocessed to make more remaining fuel available for use. Reprocessing of fuel is carried out in several nations now. Mostly they use the PUREX process using aqueous and other solvent methods to separate the components in the used fuel such as plutonium; uranium; fission products; minor actinides and fuel element jacket materials such as zirconium.

PUREX type methods have been superseded by more compact methods called pyroprocessing where necessary reactions are carried out in molten salts. Typical examples [16, 17] have been developed for current needs such as producing MOX (mixed plutonium and uranium oxide fuel) for today's LWRs. It is relatively straightforward to adapt this high temperature technology to MSRs to separate components in the fuel-coolant mix in on-line fuel processing equipment. The most up to date technical information seems to be in Wikipedia [18] although reference [19] is almost equally useful in providing current information. For example, Ref. [18] provides a clear explanation of 'veloxidation', which is especially important in removing, at an early stage, the troublesome contaminant Tritium as tritiated water. 
Pyroprocessing has all the advantages experienced in MSRs. The reactants avoid radiation damage as they are in the ionic state. The equipment illustrated in Refs. [16, 17] is compact and this factor is of much assistance in designing on-line fuel processors for MSRs.

Although pyroprocessing is superior to PUREX-type methods, PUREX has not been used much in traditional reactor technology. The reason for this is that there is an oversupply of PUREX facilities. In America, in particular, it is found cheaper to store spent fuel elements in cooling ponds, rather than reprocess the fuel. In an age of airborne suicide-terrorists this presents many soft targets and, like the problem described in section 8.4, it is a disaster waiting to happen.

\subsection{The threat from PWRs}

More than 400 aging PWRs are operating worldwide. Many of them have exceeded their design life of 40 years and are being licensed for a further 20 years or so. To economists this is a very attractive idea: where can one get a fully operating power station for no capital cost? Very rightly Caldicott has condemned this practice [2, pp. 81-86]. Another serious event like Chernobyl or Fukushima could cause the complete loss of public support for nuclear power before new systems like MSRs have a chance to prove themselves.

Just one case, involving the Davis-Besse reactor [20] near Toledo, Idaho illustrates the risks from aging plant. Quoting Caldicott [2]:

'to their horror the inspectors came upon a cavity, where corrosion had eaten its way through 6 inches of carbon steel on top of the six and a half inch reactor pressure vessel. Less than half an inch of stainless steel liner of the reactor remained intact..... This stainless steel liner was bulging outward but luckily had not ruptured. ... over time boric acid ate its way through ...creating a hole 4 x 5 x6 inches....'

One might add to this that the water in the reactor was under 150 atmospheres pressure. Hot water, as flashed and highly radioactive steam, would have jetted out from the hole exposing the reactor core to meltdown. The collateral damage to the reactor exterior equipment and the resulting meltdown of the core from such a rupture would have been catastrophic, especially in the light of other deficiencies noted by the inspectors. The conclusion is that we need to replace all our old pressurised water reactors with MSRs. We can see the benefit of using MSRs that do not operate under any pressure.

\subsection{The need for a specialised journal in MSR technology}

Considering its size, the nuclear industry does not have as many scientific journals as in many other areas of science/technology. Reliance is placed mainly on technical reports written within different private organisations. Also, although MSR technology derives from earlier nuclear science, it is now a distinct and separate branch of technology and we need a better form of communication of new ideas and concepts. Although it needs a printed form for papers of general interest, much of important edited discussion could be collected and referenced electronically to an open membership.

\subsection{Rational industrial development}

Reference [4] suggested that the future MSR industry should best develop into three competing global corporations. 
Although the corporation to satisfy Asian needs seems likely to become totally MSR based, the other two may well opt for molten lead fast reactors to burn up nuclear waste [21]. It is suggested that this alternative technology has an advantage in Europe/Russia. Although Russia has much experience in many branches of nuclear technology including MSRs, it is particularly strong in molten lead cooled reactor experience. This has a long history starting with the use of these fast reactors in Russian submarines.

The other major corporation serving the Americas could also opt for the fast lead cooled reactor. The Westinghouse corporation has plans for LFRs and there is a tendency to try to preserve encapsulated fuel technology in many American development projects, Possibly this is because fuel element manufacture generates a large financial turnover in United States industry.

\section{DISCUSSION}

South East Asia, and indeed most of East Asia generally, suffers from significant air pollution and the problems seem to get worse as one moves closer to Beijing. Replacing outdated coalbased industries with a nuclear powered economy would overcome these problems to a very large extent.

The main problem is the adverse effects on human health of the very small (e.g. PM 2.5) particles, which are invisible but are easily inhaled into the lower parts of our lungs where they tend to lodge permanently. Lung cancers resulting from this are the most deadly consequence but there are a whole range of other respiratory disorders, which are related to air pollution. Even other ailments such as cardiovascular disease and kidney failure correlate statistically with air pollution levels [22-24].

Although Australia may give an impression of a land of clean air, this is not the case. Our sprawling industrialised cities have inadequate air quality. Much more serious than this is the fact that the worst conditions by far are for people who live close to the extreme dust levels resulting from open-cut mining. Our Government officials, who are supposed to help with health matters, as well as our industrialisation, seem to be oblivious to the resulting health effects [25] of dust.

PM 2.5 particles can travel enormous distances and they are no respecter of national boundaries. At least sometimes this air pollution is visible. The smoke from burning vegetation in Indonesia is certainly very apparent in nearby Malaysia. This smoke contains a whole range of polycyclic aromatic hydrocarbons. Some of these are known carcinogens and a few are mutagenic and cause live birth defects [26, 27].

Beijing needs no further comment, except a sigh of relief that China has decided to invest heavily in MSR technology. One wonders by how much China will be able to reduce its future health-care expenditure by investing in MSR technology.

\section{CONCLUSIONS}

After considering up to date literature, it seems to the present writer that the most attractive management strategy for developing MSR technology would be along the following lines.

1. Introducing mass-marketing of a versatile thermal MSR along the lines described in Ref [4] would seem to be our highest priority. Such a development can start immediately. The future MSR industry needs such a reliable product to establish itself. Only limited service industries, such as those described in the present paper would be needed in the first few years of operation. 
2. The refurbishing of 40 year old reactors should be discouraged. Likewise the continuing storing of used fuel elements in lieu of reprocessing is even more dangerous in a terrorist-prone society. We need to accelerate development of our nuclear waste disposal industry.

\section{APPENDIX I: NOTES ON SYMBOLS USED IN FIGURE 1}

$\mathbf{R}$ is the reactor core itself. This thin-walled metal vessel must be protected in some way from fast neutron damage. This protection may be a breeder blanket of Thorium or natural/depleted Uranium. In fast reactor designs often the primary heat exchangers (PHE) are clustered round the core $\mathrm{R}$ to give better protection.

PHE is a primary heat exchanger. It is always very radioactive and heavily shielded.

$\mathbf{P 1}$ is a primary molten salt pump. Normally they are located at the top of the reactor for easy replacement access. They can also be located outside the core.

$\mathbf{T} 1$ and $\mathbf{T} 2$ are molten salt temperatures leaving and entering the core.

C.R. are control rods, which are in fact neither necessary nor used in MSRs. Occasionally one might need an epithermal neutron spectrum (e.g.100e.v.-100 ke.v.) in a reactor for special purposes Sometimes an epithermal spectrum is advantageous, and a graphite control rod can be used for this purpose. Normally insertion of this would increase reactivity. This is the reverse of the effect in an old-style reactor, which uses rods based on neutron absorption and not neutron moderation.

m.u. is the make-up extra fuel injection point to keep the reactor 'just critical'.

R.P. is the fission product extraction/clean up system and newly-bred fuel injection system. Some development work is needed for this component. Fast reactors are much more tolerant of fission product build up compared with thermal reactors. See Ref, [4] for the special needs of Protactinium-233 relating to residence time in thermal reactors [28].

F.P.G.R. Gaseous fission product gases are collected here. ${ }^{135} \mathrm{Xe}$ and Tritium are especially important. Tritium is notorious for leaking through industrial plant walls and great care is needed in design adequacy. Recycled Helium gas is also normally injected at the base of the reactor to help collect insoluble fission products such as Tellurium, which are filtered out at the top of the reactor. Without this feature some fission products tend to 'plate out' on the inner surfaces of the reactor. This process of using Helium in this way is called sparging.

SHE is a secondary heat exchanger in a low radioactive area of the plant. It normally uses a different eutectic molten salt mixture.

T/G steam turbine, generating electricity

C condenser returning feed water to SHE via P3. The steam cycle is conventional but more complicated than shown in Figure 1, such as with regard to feedheaters.

\section{APPENDIX II: ACRONYMS}

FSMSR fast spectrum molten salt reactor.

LWR liquid water moderated and cooled reactor (includes boiling and pressurised types.

MSR molten salt reactor (general term). 
PWR pressurised water reactor.

Depleted Uranium. ${ }^{238} \mathrm{U}$, a residue when fissile ${ }^{235} \mathrm{U}$ isotope is extracted from natural Uranium. It has limited uses in anti-tank artillery but is a more usefully valuable as a fertile material for breeding more Plutonium fuel in fast reactors.

\section{APPENDIX III: USING A SUBCRITICAL REACTOR TO REDUCE FINAL TRACES OF ACTINIDES IN NUCLEAR WASTE}

Subcritical reactors are the safest of all reactors as they need an external source of neutrons to work at all. Normally this source is provided by a proton accelerator [29] which targets a heavy metal target within the reactor. The numerous fast neutrons produced by this spallation effect starts this chain reaction but the fission dies away quickly because the chain reaction cannot be sustained once this source of neutrons is removed.

Even with modern technology nuclear waste needs storage for more than 300 years. After such a long time, it is possible that regulations for discarding nuclear waste may have changed. Thus it may be necessary to reduce the radioactivity from waste still further several hundred years in the future. This consideration presumes that we will have some future descendants still living in a civilised world. Should this be the case it seems likely that they will feel outraged at the profligate irresponsibility of their ancestors of our own time. Consequently our descendants may well demand higher environmental standards. The best way to secure further improvement of the quality of nuclear waste is to use a machine designed along the following lines:

After extracting transmuted elements as described in section 7, the waste in stainless steel drums is mixed with Thorium and fitted with a centrally mounted tube, open at the top of the drum but with a small piece of lead in the base which is located so that it is in the centre of the drum. The drums travel on a carousel and are pulsed consecutively by a proton accelerator [29] to produce a burst of fast neutrons to cause ${ }^{233} \mathrm{U}$ to be formed from the dispersed Thorium. This accumulates as the carousel rotates and causes fast fission of ${ }^{233} \mathrm{U}$ in the drum to reduce remaining trace actinides. Each drum is scanned for gamma radiation as it passes on the carousel to assess the remaining actinide content requiring treatment. ${ }^{233} \mathrm{U}$ itself produces very few actinides when it undergoes fission. The machine could be completely automated to removes a drum automatically when the waste meets the required specification. The machine would then fill the vacant space with a fresh drum needing treatment.

Such a device could carry out its task without human supervision.

\section{REFERENCES}

[1] Adams, R., ThorCon- Demonstrated molten salt tech packaged with modern construction techniques, January 6th, 2015, available at: http//atomicinsights.com/thorcondemonstated-molten sat-tech...

[2] Caldicott, H., Nuclear power is not the answer, The New Press: New York \& London, pp. 1-221, 2006.

[3] MacPherson, H.G., The molten salt reactor adventure. Nuclear science and Engineering, 90, pp. 374-380, 1985. https://doi.org/10.13182/nse90-374

[4] Boothroyd, R.G., Integrated molten-salt nuclear reactor systems for base-load power plants. International Journal of Energy Production and Management, 2(1), pp. 39-51, 2017.

https://doi.org/10.2495/eq-v2-n1-39-51 
[5] Boothroyd, R.G., A suggested roadmap for world-wide energy resource planning and management. International Journal of Energy Production and Management, 1(1), pp. 72-86, 2016.

https://doi.org/10.2495/eq-v1-n1-72-86

[6] Merle-Lucotte, E., Heuer, D., Allibert, M., Brochenko, M., Capellan, N. \& Ghetta, V., Launching the thorium fuel cycle with molten salt fast reactor Proceedings of ICAPP Conference, Nice, France (Paper 11190), May 2-5, 2011.

[7] Holcomb, D.E., Flanagan, G.F., Patton, B.W., Gehin, J.C., Howard, R.L. \& Harrison, T.J., Fast spectrum molten salt reactor options. Oak Ridge National Laboratory (UT-Battelle, for DOE), ORNL/TM-2011/105, July, 2011.

[8] Merle-Lucotte, E., et al. (LPSC MSFR team), The concept of fast spectrum molten salt reactor, (MSFR), French-Swedish seminar on future nuclear systems. KTH- Stockholm, Sweden, 2013, available at: www.institutfracais-suede.com/wp...Stockholmseminar-msfr-eml-03122013.pdf

[9] Endicott, N., Thorium-fuelled molten salt reactors. Report for the All party Parliamentary Group on Thorium Energy, Weinberg Foundation, London, June 2013.

[10] Ignatiev, V., GIF reactor system development status: molten salt reactor. 10th GIF INPRO IAEA Interface meeting, Vienna, Austria, 11 April, 2016.

[11] World Nuclear Association, Molten Salt Reactors (updated 30 September 2016) pp. 1-11, available at: http://www.world.nuclear.org/informatiom-library ...

[12] Ignatiev, V.V., Feynberg, O.S., Zagnitco, A.V., Merzlyakov, A.V., Surenkov, A.I., Panov, A.V., Subbotin, V.G., Afonichkin, V.K., Kohkhlov, V.A. \& Kormilitsyn, M.V., Molten salt reactors: new possibilities, problems and solutions, Atomic Energy, 112(3), pp. 157-165, 2012.

https://doi.org/10.1007/s10512-012-9537-2

[13] Anon., Do molten salt reactors have a lithium problem? The Alvin Weinberg Foundation, London, available at: www.the-weinberg-foundation.org/2013/06/04/do-molten... (accessed June 4th, 2013).

[14] Mathieu, L., Heuer, D., Brisot, R., Le Brun, C., Liatard, E., Loiseaux, J.-M., Meplan, G., Merle-Lucotte, E., Nuttin, A. \& Wilson, J., The thorium molten salt reactor: moving on from the MSBR. arXiv:nucl-ex/0506004c1, 2 June 2005.

[15] Forsberg, C.W., Thermal and fast-spectrum molten salt reactors for actinide burning and fuel production, Oak Ridge National Laboratory and American Nuclear Society manuscript 175768, Global 07 Conference, Boise Idaho, September 9-13, 2007.

[16] Inoue, T. \& Koch, L., Development of pyroprocessing and its future direction. Nuclear Engineering and Technology, 40(3), pp. 183-190, 2008.

https://doi.org/10.5516/net.2008.40.3.183

[17] Lee, H., Park, G-I., Kang, K-H., Hur, J-M., Kim, J-G., Ahn, D-H., Cho, Y-Z. \& Kim, E.H., Pyroprocessing technology development at KAERI. Nuclear Engineering and Technology, 43(4), pp. 317-328, 2011.

https://doi.org/10.5516/net.2011.43.4.317

[18] Wikipedia, Nuclear processing, pp. 1-16, updated 25/02/2017, accessed 2/03/2017.

[19] World Nuclear Association, Processing of used nuclear fuel, pp. 1-16, (updated November, 2016, www.world-nuclear.org/information-library/nuclear-fuel-cycle... 2017.)

[20] anon. Davis-Besse reactor vessel head degradation lesson, available at: https:// www.gov/reactors/operating/ops.../vessel...lltf-rpt-m1022760122.pdf 
[21] Cinotti, L., Smith, C.F. \& Sekimoto, H., Lead-cooled fast reactor (LFR) overview and perspectives, LLNL-CONF-414708 (Lawrence Livermore Laboratory) Generation IV International Forum Symposium Paris, France, September 9-10, 2009.

[22] Hendryx, M., Mortality from heart, respiraratory and kidney disease in coal mining areas of Appalachia. International Archives of Occupational and Environmental Health, 82(2), pp. 243-249, 2011. https://doi.org/10.1007/s00420-008-0328-y

[23] Hendryx, M. \& Ahern, M.A., Relations between health indicators and residential proximity to coal mines in West Virginia. American Journal of Public Health, 98(4), pp. 669-671, 2008. https://doi.org/10.2105/ajph.2007.113472

[24] Hendryx, M., O’Donnell, K. \& Horn, K., Lung cancer is elevated in coal mining areas of Appalachia. Lung Cancer, 62(1), pp. 1-7, 2008. https://doi.org/10.1016/j.lungcan.2008.02.004

[25] Boothroyd, R.G., The importance of public participation in monitoring risks in largescale industrial projects: an Australian experience. International Journal of Safety and Security Engineering, 7(1), pp. 19-30, 2017. (Also presented at 7th International Conference on Safety and Security Engineering, Rome 6-8 September, 2017.) https://doi.org/10.2495/SAFE-V7-N1-19-30

[26] Ahern, M., Mullett, M., Mackay, K. \& Hamilton, C., Residence in coal mining areas and low birth weight outcomes. Maternal and Child Health Journal, 15(7), pp. 974-979, 2011.

https://doi.org/10.1007/s10995-009-0555-1

[27] Ahern, M.A., Hendryx, M., Conley, J., Fedorko, E., Ducatman, A. \& Zullig, K.J., The association between mountaintop mining and birth defects among live births in central Appalachia, 1996-2003. Environmental Research, 111(6), pp. 838-846. https://doi.org/10.1016/j.envres.2011.05.019

[28] Tovesson, F., Hambsch, F-J., Oberstedt, A., Fogelberg, B., Ramstrom, E. \& Oberstedt, S., The Pa-233 fission cross section. Journal of Nuclear Science and Technology, 39(suppl 2), pp. 210-213, 2002. https://doi.org/10.1080/00223131.2002.10875076

[29] Nifenecker, H., David, S., Loiseaux, J.M. \& Meplan, O., Basics of accelerator driven subcritical reactors. Nuclear Instruments and Methods in Physics Research, A463, pp. 428-467, 2001.

https://doi.org/10.1016/s0168-9002(01)00160-7 